\title{
The visible men
}

\author{
Or, down the multiversal rabbit hole.
}

\begin{abstract}
Michael Moorcock
“That a cat's cradle?" Miss Brunner peered down at a naked Jerry Cornelius tangling his hands in a mess of guitar strings. A red Rickenbacker twelve lay beside him.

"It's twine theory, he said." Frank was absorbed in his own calculations covering the large slate propped on his mum's kitchen table. "He got a bit confused. Too many Es. Too much reverb." He followed her gaze. "G? Somewhere in the seventh dimension."

"He's a simple soul at heart. Easily led..."
\end{abstract} Major Nye stroked his pale moustache. He'd come in with Miss Brunner hoping to take Mrs Cornelius out. "Is she here at all?"

"Pictures with Colonel Pyat." Frank spoke spitefully. "IT at the Electric. I'll tell her you called." His horrible feet in a bowl of soapy water, he frowned over his equations. What had been in that third syringe?

"Pip," said Jerry. "Pip. Pip." The strings coiled into a neat pile and vanished. He beamed.

Frank wondered why Jerry could charm and he couldn't?

Jerry strolled into the basement room sniffing. At the window, Jerry stopped to test the bars. In the kitchen Jerry cursed as he felt about in the toaster. From the front door upstairs Jerry called through the letter box. They were all naked, save for black car-coats. Jerry stood up pulling on his underpants. "Sorry I'm not decent."

Miss Brunner turned away with a strangled word. "What...?"

"Interdimensional travel." Jerry knotted his wide tie, copping Frank's calculations. "Though not very sophisticated." $\mathrm{He}$ reached to rub out a figure.

Pettishly, Frank slapped him. "Just the air cooling. Entropy factor. Anyway, your sizes are all slightly different."

"All?" Jerry frowned at the versions of himself. "If I had a black hole they'd follow me into it. As it is..."

Frank scowled. "You and your bloody multiverse. Energy's bound to thin out if you're that profligate."

"Crap." Jerry holstered his vibragun. "Effectively energy's limitless. It's Mandelbrot, Frank. Each set's invisibly smaller. Or invisibly bigger. Depending where you start. You don't go through the multiverse - you go up and down scales of almost infinite but tiny variability. Only the mass varies enormously, making them invisible. That's why we're all essentially the same." With scarcely any echo, identical voices came from each identical mouth: "Only after travelling through billions of sets do you start spotting major differences. The quasi-infinite, Frank. Think how many billions of multiversal planes of the Universe there are! Vast as it is, with my box you can step from one end to the other in about ten minutes. Go all the way round. Your mass compresses or expands accordingly. Once I realized space is a dimension of time, the rest was easy!"

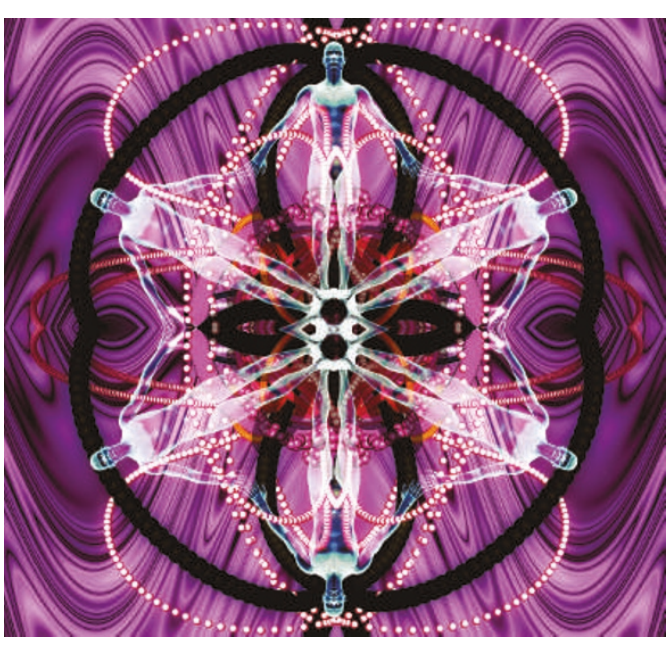

"Pervert! You and your proliferating clones."

"Clones?" Miss Brunner licked her lips. "Are they edible?" She adjusted her powder-blue two-piece.

"They're not clones, they're versions. When you dash about the multiverse, this sort of thing happens. I prefer to shrink. But denser, you rip holes; drag things in. Nobody sees the universe next door because it's too big or too small. Fractional, of course, in multiversal terms. Problem is, bits of one universe get sucked into another. They're all so close. Déjà vu...?"

"Carry on like this, young man," Major Nye straightened his cap, "and you'll cause the end of matter. You'll have your chaos, all right!" Feelings hurt, he made for the basement door.

"That's ridiculous." Miss Brunner repaired her face. "Why aren't your clones..."

"Duplicates."

"Why aren't they too big or too small to see?"

“That's the whole trick." Jerry preened. Now in sync, his rippling duplicates fol- lowed his every move. "Getting us all to the same scale. Expansion and compression. Your atoms only change mass, maintaining identity. See, we're either too huge to perceive the next universe or we're so massively tiny we merely pass through it without noticing it. Either way you can't see 'em. Until I use this little gadget."

With a disapproving pout, she clicked across the parquet.

"You change your mass relative to theirs, or vice versa, and they become visible. At first you feel a bit queasy, but you get used to it." Picking up the small black box from the table, he showed her the display, the triggers. "Have a go. It's 湈 easy. Everything's digitalized."

"Certainly not. I have enough trouble controlling my own world."

"But this gives you millions of alternatives. Immortality of sorts. Admittedly, the nearest billion or so are boringly alike. But most people, like you, love repetition..."

"Rot! Utter dissipation! Double Deutsch, I call it!” Grumpily, Major Nye closed the door. Through the bars they saw him climb area steps, pushing aside three more Jerrys staring at one another in some confusion.

Upstairs the front door opened.

"Oh, blimey!" Dismayed, Jerry peered around for a hiding place. "Mum's back early."

"You'll have some explaining to do." Frank smirked.

But Jerry was already fiddling with his box and wires. As Mrs Cornelius waddled into the room, exuding a delicious smell of greasy fish, Jerry shrank into a corner, his duplicates following. Everyone stared after him.

"Fairyland again!" Miss Brunner was contemptuous.

"The Major said Jerry 'ad a message. Where's 'e gorn?" Mrs Cornelius lifted huge blue suspicious eyes. A plump hand carried chips from her newspaper to her mouth.

"Climbing the bloody beanstalk, as usual." Defeated, Frank faded.

Mrs C roared.

Michael Moorcock claims to have invented the multiverse in 1961 but then he claims to have created London in 1965, the same year he created Jerry Cornelius, whose adventures won the Guardian Fiction Prize in 1977 despite the author's insistence of their authenticity. Colonel Pyat's final memoir The Vengeance of Rome appeared in January 2006. Moorcock is currently resting in a Texas institution. 